\title{
Sangue e sexo Menstruação e comportamento sexual
}

Maria Inês Pagano Gasperini*

"Mulher é bicho esquisito. Todo mês sangra.

Rita Lee

\section{INTRODUÇÃO}

No momento em que o homem se diferencia e ensaia perguntas sobre si mesmo, percebe que o sangue é um elemento fundamental de vida a que está presente em momentos importantes de sua existência, como no seu nascimento e, muitas vezes, na sua morte.

Torna-se, então, elemento vitalizante e sagrado ao homem a passa a fazer parte de rituais mágicos e de relacionamento com deuses a espíritos. $\mathrm{Na}$ índia o fluido sagrado era chamado 'Soma' e os padres bebiam-no em cerimônias de sacrifício. Os faraós egípcios tornavam-se divindades ingerindo o sangue de Isis. Entre os cristãos o sangue de Jesus é a forma mais elevada de amor e ele próprio deu seu sangue para a remissão dos pecados da humanidade.

* Ginecologista, Pós-Graduada em Terapia Sexual e Educação Sexual pela SBRASH.

Recebido em 12.03.99

Aprovado em 25.03.99 
Esta conotação de vida e morte, de sagrado, mágico e misterioso deu ao sangue um poderoso significado que atravessa o tempo.

A mulher, com seu sangramento mensal, assumiu, através da história, papéis os mais diversos: vidente, conselheira, bruxa, feiticeira e, atualmente, é considerada, senão uma coitada, pelo menos alguém que sofre de um incômodo.

Menstruar pode produzir na mulher sentimentos bastante contraditórios. Ao mesmo tempo em que se sente satisfeita pelo fato de 'tornar-se mulher', sabe que o preço deste status pode ser alto. Possivelmente, enxaquecas, irritações nervosas e cólicas estão à espreita. Com relação ao humor feminino, é freqüente o comentário popular: 'está assim nervosa porque vai ficar menstruada'. Ou, se é mais idosa, é por causa da menopausa. Esta visão da menstruação como algo desagradável e limitante impede que as mulheres vivam plenamente sua sexualidade e sua feminilidade.

Como a primeira menstruação tem ocorrido cada vez mais cedo, é significativo o número de mães que procuram os consultórios médicos queixando-se da menarca de suas filhas, lastimando que estas, tão precocemente, já tenham que assumir este incômodo.

Hoje o significado original de poder mágico e misterioso do sangue menstrual modificou-se. Entretanto, prevalece, ainda, a idéia de que a menstruação é impura, atrapalha e deve ser mantida em sigilo.

Neste sentido um antigo poeta inglês escreveu: "ó mulher, teus mênstruos são uma praga de que seria preciso proteger a natureza” (Apud BEAUVOIR, s/d:189). Jorge Amado, na capa do livro de autoria do médico Elsimar Coutinho (1996) "Menstruação, a sangria inútil”, assim se expressa: "Mais do que um incômodo, a menstruação é um castigo ".

\section{A MENSTRUAÇÃO ATRAVÉS DA HISTÓRIA}

Na pré-história o sangue menstrual aparece como algo mágico e místico. As mulheres, e somente elas, em determinado período de suas vidas, eram possuidoras de algo que fluía espontaneamente durante alguns dias e, inexplicavelmente, não as deixava fracas, não era doloroso e muito menos mortal.

Menstruação era um fenômeno incompreensível e inexplicável, que gerava temor e, portanto, incorporou-se ao terreno da magia, da feitiçaria e da alquimia. Esta noção manteve-se até bem poucos séculos 
atrás e, em alguns lugares do mundo, como no Tibete, mantém-se até os dias atuais.

$\mathrm{Na}$ antigüidade, judeus e pagãos acreditavam que o sangue menstrual era venenoso.

Plínio, "o velho" (79 DC), em seu tratado de História Natural, diz que a simples presença de uma mulher menstruada levaria o vinho novo a azedar, as sementes a se tornarem estéreis, os frutos a caírem das árvores e as plantas do jardim a murcharem. Segundo ele o fluido menstrual pode embotar uma lâmina de aço, matar um enxame de abelhas, enferrujar instantaneamente o ferro e o latão pelo odor ofensivo e, se, por acaso, os cães provassem do mesmo, enlouqueceriam e sua mordida seria venenosa e incurável.

No Egito, a mulher permanecia isolada durante o período menstrual. Muitas vezes ela era colocada no sótão de uma casa ou numa cabana fora da aldeia. Não se devia vê-la e nem tocá-la, nem ela própria devia tocar-se ou tocar os alimentos. Era proibida de comer. Em alguns casos, a mãe ou a irmã, por meio de um instrumento, alimentavam a menina menstruada. E todos os instrumentos, que porventura entrassem em contato com ela, deveriam ser queimados.

$\mathrm{Na}$ iniciação dos Chago, as mulheres são ensinadas a dissimularem cuidadosamente seu sangue menstrual, segundo Lévi-Strauss: "não o mostres à tua mãe, ela morreria. Não o mostres às tuas companheiras, pode haver uma maldosa que se aposse do pano com que to enxugaste e teu casamento seria estéril. Não o mostres a uma mulher má que pegaráo pano e colocará em cima de sua cabana... e não poderás mais ter filhos. Não jogues o pano no atalho nem no mato. Uma pessoa ruim pode fazer coisas feias com ele. Enterra-o no chão. Dissimula o sangue aos olhos de teu pai, de teus irmãos e de tuas irmãs. Deixá-lo ver é um pecado" (Apud BEAUVOIR, s/d:191). Entre os Aleutas, o pai não pode ver a primeira menstruação da filha, pois esta pode ficar muda ou cega. Em Saigon, não se empregavam mulheres em fábricas de ópio, pois este tornava-se amargo em presença de trabalhadoras menstruadas. A população indígena Yurok, do norte da Califórnia, isolava as mulheres menstruadas por acreditar que elas estavam no auge de seus poderes.

Os aborígenes da Austrália acreditavam que uma mulher menstruada se tornava tão contagiosa que não podia aproximar-se de alguém ou de algum objeto útil. Ela ficava proibida de sentar sobre uma canoa ou cadeira durante o período menstrual. O coito também era proibido neste período. Uma vez ocorrida a contaminação, esta só poderia ser removida se a mulher fosse morta. Já os Walbiris, habitantes do deserto australiano central, 
não têm qualquer restrição ao sangue menstrual e não existem crenças de que o contato com o mesmo traga algum perigo.

Os Mae Engas, do planalto central da Nova Guiné, temem o sangue menstrual. "Acreditam que o contato com ele ou com uma mulher menstruada fará, na ausência de uma contra magia apropriada, adoecer um homem a causará vômitos persistentes, "destruirá " seu sangue de modo que ele se tornará negro, corromperá seus fluidos vitais, de modo que sua pele escurece e se enruga, sua carne se estraga, suas faculdades mentais se embotam permanentemente e, eventualmente, conduz a um lento enfraquecimento e morte. "(Meggitt, apud DOUGLAS, 1966: 180).

Os Nyakyusas, que vivem ao norte do lago Niassa, bem como os Leles, da África, acham que o contato do sangue menstrual é perigoso para o homem, especialmente para um guerreiro que pode adoecer se a mulher menstruada cozinhar para ele.

Os anglo-saxões, no início deste século, não permitiam que as mulheres, durante o seu "curse" (maldição = menstruação), entrassem nas refinarias de açúcar, pois o mesmo pretejava. E, em 1778, o British Medical Journal publica: "É indubitável que a carne se corrompe quando tocada pela mulher no periodo das regras " (Apud BEAUVOIR, s/d: 190) baseado em dois casos de presuntos que se estragaram, quando em contato com mulheres menstruadas.

Os primitivos costumes dos índios brasileiros e africanos mandavam que as moças prestes a menstruar fossem isoladas numa cabana especial. Depois de terminada a menstruação, seus corpos eram pintados e, com cantos e danças rituais, elas eram aceitas na comunidade feminina adulta.

Bronislaw Malinowski (1983) afirma que os nativos das ilhas Trobriand, em pleno Oceano Pacífico, não têm repulsa nem receio pelo sangue menstrual. No entanto, um homem não coabita com a mulher ou a amante durante suas regras, mas permanece na mesma cabana e faz as refeições com ela. Ele apenas se abstém de deitar a seu lado na mesma cama.

No penitencial do Arcebispo Theodore de Canterbury, aplicava-se penitência de três semanas de jejum a qualquer mulher secular ou religiosa que entrasse na Igreja ou comungasse menstruada. Durante a Idade Média, a santa comunhão foi quase sempre proibida às mulheres. $E$ as que quisessem participar dos ofícios divinos eram expulsas de seu lugar na liturgia e no altar sagrado, devido à sua impureza.

No Antigo Testamento, no Levítico, Livro 3 do Pentateuco, Capítulo 15, Versículos 19 a 24, ao se referir às impurezas sexuais, o Senhor disse a Moisés a Aarão: "quando uma mulher tiver sua menstruação, ficará impura durante sete dias. Quem a tocar ficará 
impuro até à tarde. O lugar em que ela deitar ou sentar, enquanto está impura, ficará impuro. Quem tocar o leito dela deverá lavar as próprias roupas e tomar banho; ficará impuro até à tarde. (...) Se um homem tiver relações com a mulher menstruada, a impureza dela a atingirá, e ele ficará impuro durante sete dias. A cama em que ele se deitar ficará impura".

Entre os judeus ortodoxos, é costume que um homem não durma, pratique sexo ou toque em sua mulher enquanto ela estiver menstruada ou durante os sete dias de limpeza ou dias "brancos", que se seguem ao último dia do período menstrual. Após o último dia "branco" ela toma o banho de purificação ritual, o MIKWAH, e pode, então, retomar suas relações com o marido.

Os homens fiéis do Islã e instruídos pelo Alcorão devem manter-se longe das mulheres menstruadas e o coito só pode ser reiniciado depois que a mulher tomou seu banho ritual de purificação.

As antigas concepções sobre a menstruação e a mulher menstruada, embora com algumas alterações, sobreviveram à passagem dos séculos.

\section{MENSTRUAÇÃO: Mitos e tabus}

O novo dicionário da Língua Portuguesa de Aurélio Buarque de Holanda Ferreira, define menstruação como "o tempo de duração do fluxo menstrual". Ainda no mesmo dicionário "mênstruo" significa fluxo sangüíneo, em regra mensal através das vias genitais da mulher.

O mênstruo tem como sinônimos: catamenio, menorréia, regras e na linguagem popular recebe as seguintes denominações: boi, chico, conjunção, costume, pingadeira, escorrência, bode, incômodo, lua, mês, paquete, período, pingadeira do mês, sangue, veículo, visita, volta da lua, etc.

Michel Carrera, no seu livro "Sexo.- os fatos, os atos e os prazeres do amor" (1983) enumera os seguintes mitos sobre a menstruação:

- deve-se evitar lavar a cabeça durante a menstruação;

- sangue menstrual é lesivo ao penis;

- deve-se evitar praticar atletismo e natação durante a menstruação;

- as mulheres devem evitar tomar decisões importantes pouco antes ou durante o seu período menstrual;

- ao menstruarem as mulheres limpam mensalmente o corpo do sangue que não lhes serve; 
- a menstruação deixa a mulher suja, de modo que ela deve fazer uma ducha após seu período menstrual;

- as cólicas menstruais são todas de fundo emocional.

James Leslie McCary (1971) coletou uma longa lista de tabus a respeito da menstruação, de autoria do Dr. F. M. Paulsen do George Peabody College, um perito no campo do folclore:

- se um homem impotente praticar cunnilingus com uma mulher menstruada, recuperará sua potência;

- uma mulher frígida pode ser levada a vários orgasmos se mantiver relações sexuais durante sua regras;

- os animais domésticos não atenderão ao chamado de uma mulher menstruada;

- os cães alimentados por uma mulher menstruada ficarão com vermes;

- tirar os pêlos pubianos à noite garantirá à mulher um período menstrual indolor;

- no cabelo de uma mulher menstruada não "pegará" o permanente e o cabelo ondulado não pode ser alisado durante o período menstrual;

- as dores menstruais desaparecem enquanto uma mulher está sendo acariciada; a dor passará para o seu amante.

É importante ressaltar que essas informações não foram recolhidos entre pessoas analfabetas e provincianas, mas entre universitários contemporâneos de várias regiões dos Estados Unidos.

Aqui, no Brasil, uma lenda popular diz que se um namorado tomar cafezinho, servido pela sogra, misturado com o sangue menstrual da filha, este ficará enfeitiçado e casará com a moça. Ainda em nosso país, em alogumas regiões do interior, muitas proibições são mantidas e as jovens são ameaçadas com alusões do tipo:

- lavar a cabeça durante a menstruação não pode pois o sangue sobe para a cabeça;

- banhos de mar, rios ou piscinas;

- comer determinadas frutas como: banana, abacaxi, abacate;

- tomar bebidas muito geladas ou comer sorvete;

- alguns peixes considerados "carregados" como bagre e marisco;

- andar sem sapatos, "de pé no chão". 


\section{MENSTRUAÇÃO E RELAÇÃO SEXUAL}

Assim como a menstruação, as relações sexuais, neste período, também foram cercadas de inúmeros tabus, muitas vezes não recomendadas, e até mesmo proibidas através dos tempos.

A grande preocupação da época é que as relações fossem férteis, que não houvesse perda ou desperdício de esperma. Portanto, o período considerado mais fecundo do ciclo menstrual era aquele situado logo após as regras e os médicos aconselhavam suas clientes baseados nestes conceitos.

Os médicos da antigüidade, como Soranos (IAC), em Roma, em seu Tratado das Doenças das Mulheres, recomendava que as relações sexuais deveriam ocorrer não antes da menstruação "pois assim como o estômago cheio de alimento fica disposto a rejeitar aquilo que o sobrecarrega, a vomitar e a rejeitar qualquer tipo de alimento, assim também o útero cheio de sangue. Não durante as evacuações menstruais que constituem uma espécie de vômito natural onde o esperma se arriscaria, ele também a ser levado. Nem também quando o fluxo cessa completamente: o útero assim seco e frio, não está mais em estado de receber o sêmen. $O$ momento favorável é quando o fluxo está em vias de cessar, quando o útero está ainda sangüinolento, penetrado de calor, $e$, por esta razão, turgescente de apetite para acolher o esperma. Este apetite que renasce no corpo, após a purgação, se manifesta na mulher por um desejo que a leva relação sexual". (Apud FOUCAULT, 1985: 129).

Filon (II DC) argumentava que o sangue menstrual fresco mantinha o útero úmido e a "umidade não só debilita a vitabilidade do sêmen como o anula por completo”. (Apud HEINEMANN, 1988: 33)

Plínio, o velho (79 DC), proibia a relação sexual durante a menstruação pois "os filhos dela advindos eram doentes, ou tinham soro sangüíneo purulento ou eram natimortos. " (Apud HEINEMANN, 1988: 33)

Heinemann, em seu livro Eunucos pelo reino de Deus, mostra com clareza o comportamento sexual dos fiéis exigido pela igreja. Segundo ele, os padres da igreja católica Clemente de Alexandria (215 DC) e Orígenes (254 DC) alegavam que as crianças concebidas durante a menstruação nasciam deficientes. Jerônimo (420 DC) escreveu: "Quando um homem mantém relações sexuais neste período, os filhos nascidos desta união são leprosos e hidrocefálicos, e o sangue corrompido faz com que os corpos de ambos os sexos dominados pela peste, ora sejam muito pequenos, ora muito grandes". (Apud HEINEMANN, 1988: 33) 
"Quem mantiver relações sexuais com a esposa durante a menstruação" adverte o arcebispo Cesário de Arles (542 DC) "terá filhos que ou serão leprosos ou epiléticos, ou possuídos pelo demônio". (Apud HEINEMANN, 1988: 33)

Para os teólogos Tomás de Aquino, Alberto Magno e Duns Scoto, o coito com mulheres menstruadas era considerado pecado mortal, devido ao mal causado aos filhos.

Bertoldo de Rogensburgo (1272), famoso pregador da época, alerta aos fiéis: "Não tereis qualquer alegria com filhos concebidos durante a menstruação. Porque ora serão afligidos pelo demônio, ora leprosos ou então epiléticos, ou corcundas, ou cegos, ou de pernas tortas ou surdos ou idiotas ou terão a cabeça em forma de macete. " (Apud HEINEMANN, 1988: 34)

Nos séculos seguintes, a noção de deficiência foi-se modificando. No século XVI, o cardeal Caetano (1534) considerava o coito durante a menstruação como "pecado venial". Tomáz Sanchez (1610) teólogo moralista, já aceitava a relação sexual, em certas circunstâncias, sem considerá-la pecaminosa, se fosse para superar forte tentação carnal, ou atenuar brigas conjugais.

Como se pode perceber, a igreja exercia um grande poder, a ponto de, segundo o abade Reginon de Prüm de Eifel (915) e Bucardo de Worms (1025), os padres, no confessionário, deveriam indagar sobre as relações sexuais de seus fiéis durante o período menstrual.

$\mathrm{Na}$ Idade Média a medicina não tinha acesso ao corpo feminino para exames, a noção de anatomia era transmitida aos médicos pelas parteiras e pelas próprias mulheres.

A literatura científica da época no livro Anatomia Magistri Nicolai Fhisici descrevia uma veia "fêmea" cujo papel era o de conduzir uma parte do sangue menstrual à matriz e a outra parte às glândulas mamarias a fim de que fosse transformado em leite para assegurar a alimentação da criança.

Foi Hipócrates (450 AC) na sua obra Corpus Hipocrático, quem definiu as primeiras noções de biologia, anatomia e fisiologia. Nesta época, como não havia ainda dissecação de cadáveres, a idéia que se tinha do útero é que fosse subdividido formando inúmeros compartimentos e saliências, contendo tentáculos e ventosas. Trompas e ovários não eram conhecidos. Hipócrates foi também o primeiro a estudar o fenômeno menstrual e, baseado no alívio que as mulheres sentiam após a menstruação, estendeu-o a outras patologias indicando a sangria como tratamento de muitas enfermidades. Esta noção perdurou até quase os nossos dias. 
Somente no século XX é que se conheceu e se definiu corretamente a fisiologia menstrual, com a descoberta da síntese dos hormônios sexuais pelos ovários e a atuação dos mesmos no útero.

Posteriormente, a produção laboratorial destes hormônios e o aprimoramento dos métodos anticoncepcionais deram à mulher o controle da "magia", e, pela primeira vez, a possibilidade de desvincular a relação sexual da gestação. Hoje, a mulher, se quiser, controla exatamente o seu sangramento e as suas gestações.

A ciência, portanto, libertou a mulher, mas as primitivas idéias do sangue como algo "impuro" e "vergonhoso" persistem para a maioria, atrapalhando a vivência tranqüila e prazerosa das relações sexuais neste período.

Num levantamento despretencioso e sem qualquer rigor científico, realizado em meu consultório, na cidade de Florianópolis, Santa Catarina, com 340 mulheres entre 14 e 48 anos no período de julho de 1997 a dezembro de 1997 sobre relações sexuais no período menstrual, verifiquei que somente $20 \%$ delas tinham relações durante o mesmo. Apesar de um número bem maior destas mulheres revelar desejo sexual nesta época alegavam que por "nojo" ou "vergonha" não se sentiam à vontade para o ato sexual. Observei também que entre as adolescentes a freqüência de relações neste período era maior pois a menstruação funcionava para elas como método anticoncepcional.

Como se pode perceber, o período menstrual é rico em preconceitos, alimentados historicamente por aspectos sociais, culturais e religiosos. Ainda hoje, é muito grande o peso e as limitações que os tabus menstruais impões à conduta sexual das pessoas.

Parece que a menstruação de outrora, mágica e inexplicável, capaz de deificar faraós, passa, hoje, à trágica e inaceitável, mantendo-se assim valores culturais que nem mesmo a ciência consegue modificar.

\section{BIBLIOGRAFIA}

1. BEAUVOIR, S. O segundo sexo. São Paulo, Difusão Européia do Livro, s/d. (Vol. 1).

2. CARRERA, M. Sexo: os atos e os prazeres do amor. São Paulo, Círculo do Livro, 1983.

3. COUTINHO, E. Menstruação, sangria inúlil. São Paulo, Gente, 1996.

4. DOUGLAS, M. Pureza e perigo. São Paulo, Perspectiva, 1996.

5. DUBY, G. História das mulheres. São Paulo, Afrontamento, 1990. 
6. FOUCAULT, M. História da sexualidade. Rio de Janeiro, Graal, 1985 Vol III.

7. GREGERSEN, E. Práticas sexuais: a história da sexualidade humana. São Paulo, Roca, 1983.

8. HEINEMANN, U. R. Eunucos pelo reino de Deus. Rio de Janeiro, Rosa dos Tempos, 1988.

9. MALINOWSKI, B. A vida sexual dos selvagens. Rio de Janeiro, Francisco Alves, 1983.

10. MCCARY, J. L. Mitos e crendices sexuais. São Paulo, Manole, 1971.

11. MEAD, M. Sexo e temperamento. São Paulo, Perspective, 1979.

12. NOVAES, F. A. História da vida privada no Brasil. São Paulo, Companhia das Letras, 1997.

13. PRIORI, M. D. História das mulheres no Brasil. São Paulo, Contexto, 1997.

14. ROUSSELlE, A. Pornéia. São Paulo, Brasiliense, 1983.

15. TANNAHILL, R. O sexo na história. Rio de Janeiro, Francisco Alves, 1980. 